\title{
Propuesta de evaluación de impacto de proyectos basado en el marco del paradigma de desarrollo humano: Proyecto turístico de FOMILENIO en Suchitoto
}

Rodrigo Cuadra - Alejandro Flores - Luis Orellana Universidad Centroamericana "José Simeón Cañas", El Salvador

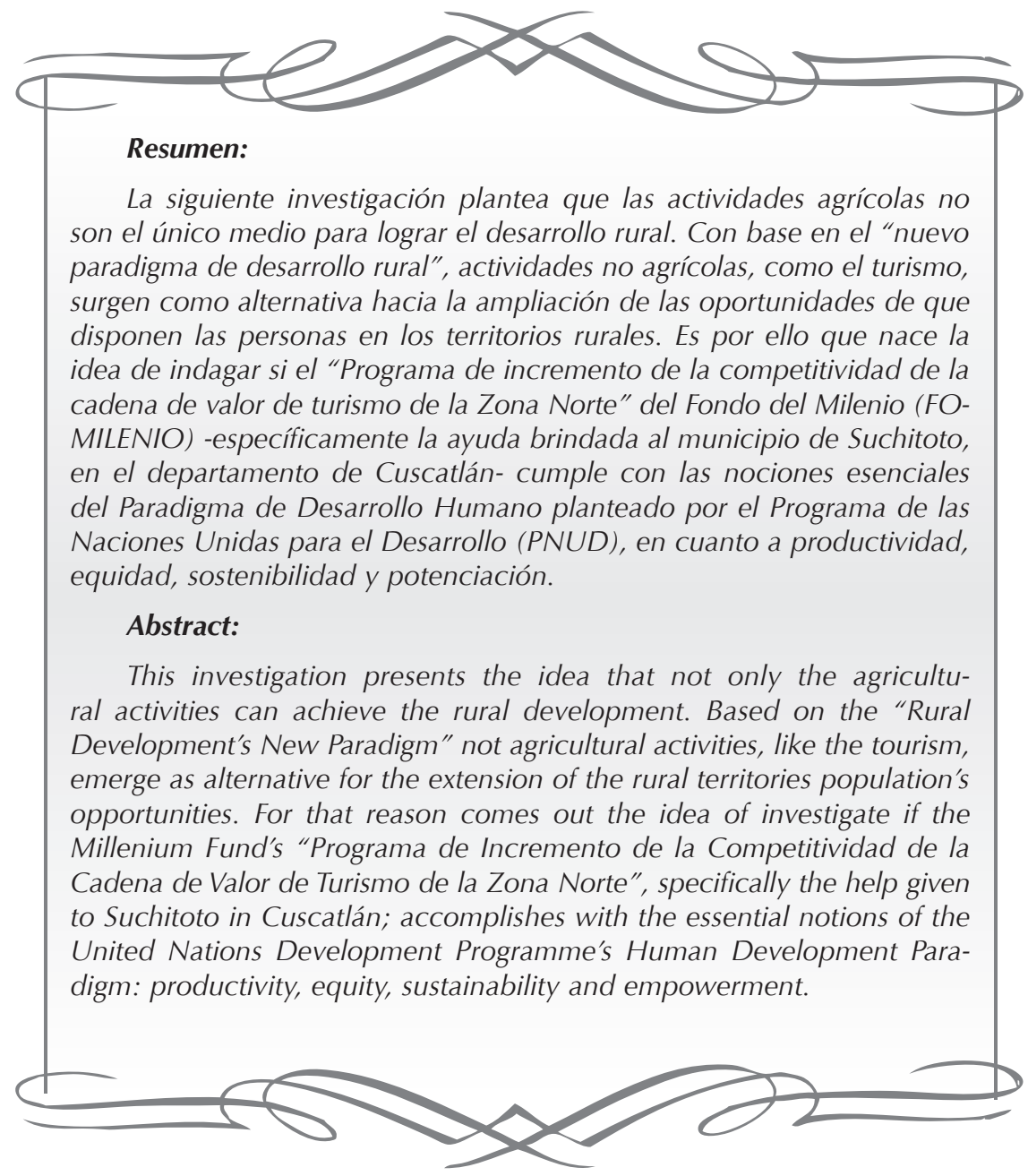


Con base en la idea del "nuevo paradigma de desarrollo rural", que plantea la no adhesión única a actividades agrícolas como medio para superar la pobreza en el ámbito rural (Ellis y Biggs, 2001; citados en Juárez y Ramírez, 2007), las actividades turísticas se perfilan como opciones de desarrollo para estas áreas.

El principal objetivo de la investigación en la que se basa este resumen ejecutivo fue indagar si la estrategia implementada en Suchitoto por el "Programa de incremento de la competitividad de la cadena de valor de turismo de la Zona Norte" de FOMILENIO permitió la ampliación de oportunidades de las personas de dicho municipio, de acuerdo con las nociones esenciales del paradigma de desarrollo humano: productividad, equidad, sostenibilidad y potenciación.
A continuación se presentan de manera resumida los principales elementos de dicha investigación. Se inicia definiendo los conceptos que fundamentan el aporte del turismo rural al desarrollo económico y social de territorios no urbanos. Luego, se describe la estrategia implementada por FOMILENIO para potenciar la cadena de valor de turismo de Suchitoto. Después, se muestran los resultados de la evaluación realizada a dicha intervención, los cuales fueron obtenidos mediante el análisis de instrumentos utilizados para determinar si el programa cumplía con los cuatro componentes del paradigma de desarrollo humano. Finalmente, se exponen las conclusiones de la investigación y recomendaciones de cara a la formulación de futuros proyectos que pretendan el desarrollo de zonas rurales.

\section{Conceptos importantes}

\subsection{Ruralidad}

Tal como describen Perico y Ribero (2002: 26), lo rural se ha formado con base en una "compleja interrelación de dimensiones sociales, económicas, culturales y políticas, ha sido un proceso histórico que se ha ido tejiendo en siglos de apropiación de territorio". Los mismos autores resaltan el papel determinante de las actividades primarias en el desarrollo del medio rural. Plantean que la agricultura es el:

factor de construcción de sociedades asentadas en territorios con organización estable y permanente (...) la agricultura no solamente es responsable de haber provisto los alimentos necesarios para la supervivencia de estos grupos sino que adicionalmente determinó la localización de estos y las características y condiciones de su desarrollo social e institucional, 
relación de dominación y relación de uso o explotación de los recursos que estaban a su disposición de una forma permanente y estable. (Perico y Ribero, 2002: 30)

De esta forma, la base agraria es fundamental al hablar de ruralidad; sin embargo, esta visión ha trastocado la posibilidad de entender al medio rural desde una postura más amplia, ya que éste suele limitarse a actividades puramente agrícolas, contribuyendo a formar una dicotomía entre lo rural y lo urbano. Según Pérez (2001), esta dicotomía surge y se refuerza con la idea de progreso gestada desde el siglo XVIII y se afianza en la Revolución Industrial. Bajo las concepciones convencionales de progreso económico, las transformaciones estructurales de los distintos modelos económicos llevan a una evolución que va desde lo rural hacia lo urbano, de lo agrícola a lo industrial, conduciendo a la idea de trasfondo de lo atrasado a lo moderno (Pérez, 2001: 3).

Muchos conceptos poseen elementos suficientes como para comprender lo rural en un sentido amplio. En la investigación de Amaya et al. (2010) se retoman algunos como el de Ceña (1993) quien define al medio rural como "el conjunto de regiones o zonas con actividades diversas (agricultura, industrias pequeñas y medianas, comercio, turismo, etc.) y en las que se asientan pueblos, aldeas, pequeñas ciudades y centros regionales..." (Ceña, 1993; citado en Amaya et al., 2010).
El Instituto Interamericano de Cooperación para la Agricultura (IICA) (2000), desde la década de los 80 del siglo XX, ha impulsado el concepto denominado "La Nueva Ruralidad", que está centrado en tres elementos: diferenciación, reforma y complemento (Perico y Ribero 2002, citados en Amaya et al., 2010). Ampliando estas ideas desde la visión institucional del IICA, Perico y Ribero (2002: 30) exponen que:

- Respecto a la diferenciación, las políticas y en general las estructuras de planificación siempre han generado procesos de desarrollo sectorial determinados por visiones duales sobre lo urbano y lo rural.

- En lo referente al elemento de complemento, plantean que la construcción de sociedades y las formas de ocupación de sus territorios han estado ligadas a la explotación y uso de sus recursos naturales.

- En referencia al elemento de reforma, en igual medida las instituciones formales o informales y de toda índole presentes en los territorios rurales, componen ciertamente un elemento de la riqueza social rural, las cuales en la generalidad han sido subutilizadas. 
Al integrar todos los elementos mencionados, el IICA define a la nueva ruralidad de la siguiente forma:

Una propuesta para mirar el desarrollo rural desde una perspectiva diferente a la que predomina en las estrategias de política dominantes en los gobiernos y organismos internacionales (...). Parte de la redefinición de lo rural e invita a la reconsideración de la visión de que lo rural es población dispersa centrada en el sector agropecuario, para pasar a la reconstrucción del objeto de trabajo y de política al definir el ámbito rural como el territorio construido a partir del uso apropiado de los recursos naturales, donde se generan procesos productivos, culturales, sociales y políticos (...). (IICA, 2000; citado en Amaya et al., 2010)

Con base en la idea de "La Nueva Ruralidad", es posible pensar en un desarrollo nacional integral que reúna los diversos elementos que comprenden el ámbito de lo rural -el cual ha sido tomado como algo secundario- y que a la vez conforme un desarrollo integrador junto al medio urbano.
En la investigación, se tomaron en cuenta los elementos sobre ruralidad que permitieran obtener, analizar y operar la información y hallazgos de la misma. De esta forma, el grupo de investigación entiende ruralidad como:

El conjunto de regiones o zonas cuyo orden histórico y social es fruto de procesos largos de organización histórica y territorial, donde confluyen diversas actividades mediante las cuales se interrelaciona la población en las esferas sociales, políticas, culturales y económicas. Estos territorios están caracterizados por espacios cuyos recursos naturales son considerables en cuanto a cantidad y diversidad, además de infraestructura como viviendas, centros educativos, servicios básicos que en general se encuentran en un estado disperso.

Esta definición se construyó con el fin de delimitar un espacio rural de forma concreta. Además sirvió de fundamento para el supuesto que se asumió en la investigación, donde se consideró a Suchitoto como un espacio rural en su totali- dad. Para reforzar este supuesto, se toman como base los resultados del VI Censo de Población y V de Vivienda 2007, los cuales describen la estructura particular de la población de Suchitoto. Dichos resultados se resumen en la tabla 1: 


\section{Tabla 1}

\section{Población del departamento de Cuscatlán y del municipio de Suchitoto}

\begin{tabular}{|c|c|c|c|c|c|}
\hline \multicolumn{4}{|c|}{ Departamento y municipio: } & Cuscatlán & Suchitoto \\
\hline \multirow{11}{*}{$\begin{array}{l}\frac{0}{0} \\
\frac{\pi}{0} \\
\frac{0}{0}\end{array}$} & \multirow{3}{*}{$\overline{\mathfrak{0}}$} & \multicolumn{2}{|c|}{ Total } & 231,480 & 24,786 \\
\hline & & \multicolumn{2}{|c|}{ Hombres } & 111,096 & 12,217 \\
\hline & & \multicolumn{2}{|c|}{ Mujeres } & 120,384 & 12,569 \\
\hline & \multirow{8}{*}{$\frac{\Xi}{\frac{\pi}{2}}$} & \multirow{3}{*}{ 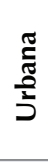 } & Total & 96,692 & 7,654 \\
\hline & & & Hombres & 45,313 & 3,558 \\
\hline & & & Mujeres & 51,379 & 4,096 \\
\hline & & \multicolumn{2}{|c|}{$\%$ Población urbana } & $42 \%$ & $31 \%$ \\
\hline & & \multirow{3}{*}{ 突 } & Total & 134,788 & 17,132 \\
\hline & & & Hombres & 65,783 & 8,659 \\
\hline & & & Mujeres & 69,005 & 8,473 \\
\hline & & \multicolumn{2}{|c|}{ \% Población rural } & $58 \%$ & $69 \%$ \\
\hline
\end{tabular}

Fuente: Elaboración propia con base en el VI censo de Población y V de Vivienda 2007 (GOES, 2008).

En la tabla 1 se muestra que la población del municipio de Suchitoto está compuesta en un $69 \%$ por habitantes de zonas rurales y que a nivel departamental la población rural representa un $58 \%$ del total. ${ }^{1}$ Esto refuerza el supuesto planteado para la investigación, en el que se clasificó al municipio de estudio como un territorio rural.

\subsection{Desarrollo}

Según Gutiérrez (2007), en el proceso teórico por avanzar hacia una visión integral del desarrollo que incluya, además de la visión económica, la dimensión social, política y cultural, surge a principios de los años noventa una nueva forma de medir el desarrollo que superó las mediciones tradicionales, haciendo referencia a un "nuevo paradigma de desarrollo humano".

El Programa de las Naciones Unidas para el Desarrollo (PNUD) define al desarrollo como "un proceso conducente a la ampliación de las opciones de que disponen las personas" (PNUD, 1995: 15). El PNUD (1995) considera como opciones esenciales tener una vida larga y saludable, acceder a conocimientos y recursos necesarios para disfrutar de un nivel de vida decoroso. De igual manera, los componentes principales de este nuevo paradigma de desarrollo son: 
- Productividad: Posibilitar el incremento de la productividad de las personas y de su participación en la generación de ingresos y el empleo remunerado.

- Equidad: Todas las personas deben tener igual acceso a oportunidades.

- Sostenibilidad: Asegurar el acceso a oportunidades tanto a la generación actual como a las futuras. Implica reposición de capital físico, humano y medioambiental.

- Potenciación: Las personas deben tener un rol activo en su desarrollo, no sólo ubicarse como destinatarios pasivos de asistencias externas (PNUD, 1995: 16).
Por otra parte, es un hecho contundente que el espacio rural en los países americanos ha venido evolucionando enfrentándose a un nuevo escenario rural. Dicho escenario se basa en el carácter territorial que permite visualizar los asentamientos humanos y sus relaciones de tipo rural-urbano, junto con el desarrollo progresivo de actividades agrícolas no tradicionales y actividades no agrícolas en el medio rural (IICA, 2000). Por tanto, tomando en cuenta la reconfiguración e importancia que actualmente representan los espacios rurales, se definió lo que para objeto de la investigación se entendería como Desarrollo Rural Sostenible. Teniendo en cuenta el enfoque de "Nueva Ruralidad" en la construcción de un desarrollo rural sostenible, se plantea:

la necesidad de definir políticas sobre la concepción, las estrategias y las prioridades del desarrollo nacional, regional y local teniendo en cuenta las implicaciones con la cadena agroproductiva-comercial y lo rural y los relacionamientos con los programas y políticas de reformas económicas, reformas del Estado, políticas macroeconómicas, y otras que inciden en la ruralidad. (IICA, 2000: 10)

Atendiendo al enfoque de "La Nueva Ruralidad" y la visión integral de desarrollo que se menciona anteriormente, se define al Desarro-
Ilo Rural Sostenible -que sienta la base para la búsqueda del "nuevo paradigma de desarrollo rural" que se estudiará- de la siguiente manera:

Proceso de transformación de las sociedades rurales y sus unidades territoriales, centrado en las personas, participativo, con políticas específicas dirigidas a la superación de los desequilibrios sociales, económicos, institucionales, ecoló- 
gicos y de género, que busca ampliar las oportunidades de desarrollo humano. (IICA, 2000: 15)

Este proceso plantea que las sociedades en su conjunto deben encontrar un balance que significa mejorar la calidad y el nivel de vida de los habitantes dentro de respectivos límites impuestos por los ecosistemas locales, regionales y globales (IICA, 2000), considerando a todas las generaciones, acentuando así el carácter sostenible de esta visión de desarrollo rural.

A la luz de esto, y para el caso salvadoreño, la Fundación Salvadoreña para el Desarrollo Económico y Social (FUSADES) -en el informe económico "Crecimiento con participación: Una estrategia de desarrollo para el Siglo XXI" (1999)- promueve las inversiones en infraestructura para potencializar la economía rural no agropecuaria con el fin de incrementar los ingresos percibidos por este sector.

De esta forma, en la investigación se optó por un "nuevo paradigma de desarrollo rural" que integrase al territorio rural con su interior y con el resto de la economía nacional, propiciando su revitalización y reestructuración progresiva mediante la estructuración de encadenamientos de valor articulados a los territorios (Herrera, 2012) y sus actividades productivas tradicionales.
En este sentido, la estrategia de desarrollo vendrá dada por la capacidad de generar nuevas actividades productivas dinámicas. Para lograr esto, será necesario que las actividades productivas tradicionales se relacionen con la demanda que una nueva actividad genera en otras (encadenamientos productivos hacia atrás), así como con las posibilidades que ofrece para desarrollar otras actividades (encadenamientos productivos hacia adelante) (CEPAL, 2011).

Se consolida así la visión de desarrollo rural sostenible que guió la investigación, la cual reconoce la importancia de la potenciación de los territorios rurales, la búsqueda de nuevas actividades productivas vinculadas a las actividades tradicionales y el rol activo de mujeres y hombres como actores de su propio destino, hacia la construcción de un nivel de vida decoroso sin comprometer las oportunidades tanto de la generación actual como de las futuras.

Esta visión, que parte del concepto de ruralidad propuesto en la investigación, pretende ser integradora de espacios, agentes, mercados y políticas públicas de intervención, fortaleciendo la concepción multidimensional en la que lo ambiental, lo económico, lo social, lo cultural y lo político-institucional 
interactúan y se convierten en ejes fundamentales del desarrollo rural sostenible (Herrera, 2012).

\subsection{Turismo rural}

Tal como cita Chalabi (2009), en la definición oficial manejada por la Corporación Salvadoreña de Turismo (CORSATUR), el Ministerio de Agricultura y Ganadería (MAG) y el Ministerio de Medio Ambiente y Recursos Naturales (MARN), se entiende por turismo rural al "conjunto de actividades turísticas que se realizan en los medios rurales y que se basan en las ventajas que presenta el entorno natural y humano específico de esas zonas. Pertenecen a esta categoría el ecoturismo, el turismo de aventura, el etnoturismo y el agroturismo" (CORSATUR; MAG; MARN citado en Chalabi, 2009).

Bringas (2008) afirma que el turismo rural dinamiza las actividades económicas tradicionales y valoriza las particularidades culturales locales, a la vez que crea nuevas oportunidades de empleo de la población local, contribuyendo a frenar el éxodo rural. Existe una diversidad de actividades turísticas que se agrupan bajo la clasificación de turismo rural. Según el artículo de Bringas (2008), se dividen dependiendo del territorio y de la temática concreta de las actividades, tales como:
- Agroturismo

- Ecoturismo

- Turismo de aventura

- Turismo religioso

- Turismo cultural o histórico

Según Gómez y Ortíz (2010), la actividad turística en Suchitoto inició a principios de los años noventa, sobre todo en la zona central donde se concentra la infraestructura histórica, hoteles, restaurantes y servicios. Esta actividad es tan relevante para el municipio que incluso se ha creado una institucionalidad local que la respalde y se han diseñado planes y proyectos para fortalecerla, dejando en evidencia que la municipalidad ha identificado en el turismo una estrategia de desarrollo local. Entre las actividades realizadas y las instituciones apoyadas por la municipalidad en pro de la actividad turística están: la Oficina Municipal de Turismo, la Oficina Técnica del Conjunto Histórico, el Comité de Desarrollo Turístico de Suchitoto (CODETURS) y el Centro Turístico Puerto San Juan (Gómez y Ortíz, 2010: 18).

Bajo el marco del Proyecto de Desarrollo Productivo (PDP) de FOMILENIO, que hace parte de los muchos proyectos destinados a potenciar la zona norte de El Salvador, se desarrolla el Programa de incremento de la competitividad de la cadena de valor turismo, en el cual se centró la investigación. En Suchitoto, el proyecto potencia 
principalmente el turismo cultural y el turismo histórico (Chemonics International, 2010a).

\subsection{Análisis insumo-producto}

A continuación se presenta el desarrollo teórico que enmarca el análisis insumo-producto, bajo el cual se desarrolló un ejercicio práctico cuyo objetivo fue visibilizar las sinergias establecidas entre las cadenas de valor apoyadas por el proyecto de FOMILENIO.

Según Escobar (2006), el análisis insumo-producto ha estado presente desde las primeras reflexiones económicas hechas en la historia. Además, afirma que aunque dicho análisis ha centrado su estudio en las condiciones que garantizan una consistencia mutua entre insumos a utilizar y productos a ofrecer para todas las ramas productivas de una economía, las razones por las que se ha llevado a cabo no han sido siempre las mismas.

Sin embargo, el enfoque retomado en la investigación diferencia entre el análisis de las condiciones de equilibrio "horizontal" o intrasectorial; o dicho de otra manera: entre los productos finales destinados a satisfacer los deseos de los consumidores y el análisis de proporciones "verticales", el cual no se determina por la demanda de los consumidores sino por las relaciones tecnológicas asociadas al hecho de que el output de algunas industrias sirven -completamente o en parte-, como inputs en el proceso de producción de otros bienes. Este tipo de análisis "vertical" es, de hecho, el tema central del análisis insumo-producto en sentido estricto (Escobar, 2006).

Para los intereses de la investigación, se tomó de referencia los aportes realizados por W. Leontief. Gracias a ellos, este análisis se conoce actualmente como análisis insumo-producto, y alrededor de los mismos convergen todos los desarrollos previos y posteriores sobre el tema.

De acuerdo a Escobar (2006), el trabajo de Leontief trata del análisis de la interdependencia de las diversas industrias o ramas productivas de una economía expresadas en un sistema de ecuaciones lineales; y específicamente, de cómo se asigna, entre el resto, el producto de cada una de dichas industrias. La misma fuente afirma que la obra de Leontief rescata de los economistas clásicos, incluido Marx, el intento de explicar los flujos económicos anuales y las condiciones que permiten su repetición periódica; también recoge aportes de Walras, sobre todo el de los coeficientes de producción que relacionaban la cantidad de factores requeridos para producir una unidad de un producto particular.

Entre las distintas utilidades que pueden obtenerse de la Matriz Insumo-Producto (MIP), se pueden 
mencionar las siguientes (Panigo, 2000):

- Determinar los flujos que constituyen la oferta y demanda de bienes y servicios de todos los sectores de la economía.

- Proyectar la tasa de crecimiento del producto en los próximos años.

- Medir el grado de desarrollo de un país, a partir del grado de participación de las manufacturas y servicios en el total del valor agregado.

- Estimar la distribución funcional del ingreso.

- Medir el nivel de competencia en los mercados.

Este modelo es usualmente construido con datos económicos de un período determinado y de una región específica, cuya economía es agrupada según el criterio de "industria", es decir, industrias que producen bienes intermedios para el proceso productivo de otras industrias (consumo intermedio) y bienes finales (consumo final) (Escobar, 2006).
Según Escobar (2006), la información fundamental obtenida con este análisis es sobre el flujo de productos de cada sector industrial, considerado como productor, destinado a cada sector considerado como consumidor. Esta información básica está contenida en una tabla o matriz de transacciones interindustriales, que se describen así (Escobar, 2006: 20): Las filas de dicha tabla describen la distribución del output del productor a través de la economía. Las columnas describen la composición de insumos requeridos de una particular industria. Las columnas adicionales, Ilamadas "Demanda Final", registran las ventas de los productos de cada sector hacia los mercados finales. Las filas adicionales, Ilamadas "Valor Agrega$\mathrm{do}^{\prime \prime}$, contabilizan otros inputs (no industriales) para la producción, como el trabajo. En resumen, se trata de una tabla de 3 cuadrantes, cada uno contabilizando un destino específico de la producción: el primero, el consumo intermedio; el segundo, el consumo o demanda final, refiriéndose al mercado de bienes; $y$ el tercero, el valor agregado, referido al mercado de servicios de factores (Escobar, 2006). Lo anterior puede observarse de mejor forma en la tabla 2:

Tabla 2

Estructura de la MIP

\begin{tabular}{|c|c|}
\hline CUADRANTE DE DEMANDA INTERMEDIA & CUADRANTE DE DEMANDA FINAL \\
\hline CUADRANTE DE VALOR AGREGADO & \multicolumn{1}{|c}{ CUAN } \\
\cline { 1 - 2 }
\end{tabular}

Fuente: Elaboración propia con base a SERIE Estudios Estadísticos y Prospectivos №37 (CEPAL, 2005: 8). 
Más adelante se detallan los resultados obtenidos en el ejercicio práctico que se desarrolló en la investigación que se resume en este documento.

\section{Apoyo de FOMILENIO al turismo rural}

\subsection{Millenium Challenge Corporation (MCC)}

La MCC es una agencia de cooperación de los Estados Unidos que lucha por erradicar la pobreza a nivel mundial. Fue creada por el Congreso de ese país en enero de 2004 (MCC, 2012a). Para contribuir a reducir la pobreza global a través del crecimiento económico sostenible, la MCC administra la Cuenta del Reto del Milenio (MCA por sus siglas en inglés), financiada por el Congreso de los Estados Unidos (FOMILENIO, 2012a).

\subsection{Convenio del Reto del Milenio}

La MCC anunció que los países de renta media baja podrían ser elegibles para recibir fondos de la MCA a partir del año fiscal 2006 (Montero, 2006). El 8 de noviembre del 2005, la MCC anunció que El Salvador había sido uno de los elegidos entre dichos países (FOMILENIO, 2012b).

Como resultado de un proceso consultivo realizado a diferentes sectores de la población, El Salvador propuso a la MCC un programa de cinco años que reduciría la pobreza y permitiría alcanzar el crecimiento económico a través de actividades enfocadas en la Zona Norte del país (FOMILENIO, 2012b). Las actividades se dirigirían a dicha zona porque, a pesar de que es un área con altos niveles de pobreza, es una región que ofrece una importante fuente de agua, energía, biodiversidad y recursos ambientales para El Salvador y, además, cuenta con grandes posibilidades para el desarrollo sostenible que aún no habían sido explotadas (FOMILENIO, 2012b).

La Junta Directiva de la MCC aprobó el 8 de noviembre del 2006 la propuesta que El Salvador le había presentado, con la cual se planificaba aliviar la pobreza de más de 150,000 salvadoreños y mejorar la calidad de vida de los 850,000 habitantes de la Zona Norte (FOMILENIO, 2012b). El 29 de noviembre de ese mismo año fue suscrito el Convenio del Reto del Milenio entre la MCC y el Gobierno de El Salvador (GOES) (Chemonics International, 2012a), y el siguiente mes la Asamblea Legislativa lo ratificó y aprobó de forma unánime (FOMILENIO, 2012b). Finalmente, el convenio entró en vigencia el 20 de septiembre del 2007 (MCC, 2012b), una vez FOMILENIO había sido creado y tanto el GOES como 
la MCC habían cumplido con todas las condiciones previas a la entrada en vigencia que se habían estipulado en el convenio (GOES-MCC, 2006). A partir de esa fecha, dio inicio el plazo de 5 años asignado para la implementación del proyecto (MCC, 2012b).

El Convenio del Reto del Milenio se plantea como objetivo principal "incrementar el crecimiento económico y la reducción de la pobreza en la Zona Norte de la República de El Salvador" (Chemonics International, 2012a). Según Chemonics International (2012a: 6), la MCC donó a través del convenio un total de US\$460.94 millones, los cuales servirían para financiar el logro de los siguientes objetivos:

\section{a. Objetivo de Desarrollo Hu-} mano: Incrementar el capital humano y físico de los residentes de la Zona Norte para aprovechar las oportunidades de empleo y de negocios.

\section{b. Objetivo de Desarrollo Produc-} tivo: Incrementar la producción y el empleo en la Zona Norte.

c. Objetivo de Conectividad: Reducir el costo y la duración de los desplazamientos dentro de la Zona Norte, hacia el resto del país y dentro de la región.

\subsection{FOMILENIO}

FOMILENIO es una entidad autónoma creada por el Gobierno de El Salvador para encargarse de velar por el cumplimiento de los objetivos del Convenio del Reto del Milenio y para que fuera responsable de administrar los recursos de manera eficiente y cumpliera con las responsabilidades y obligaciones que el Gobierno había asumido en el marco de dicho convenio (Chemonics International, 2012a). La creación de esta entidad, como ya se mencionó, era una de las condiciones que la MCC solicitaba que el Gobierno cumpliera para que el convenio entre ambas partes pudiese entrar en vigencia.

El decreto número 189, que establece la creación de FOMILE$\mathrm{NIO}$, fue aprobado por la Asamblea Legislativa el 20 de diciembre de 2006 y luego por el presidente de la República de ese entonces, Elías Antonio Saca, el 4 de enero de 2007, fecha en la que también se publicó el decreto en el Diario Oficial (Ministerio de Gobernación de El Salvador, 2007).

\subsection{Proyecto de desarrollo productivo (PDP)}

Este proyecto surge en respuesta al segundo objetivo del Convenio del Reto del Milenio. Su objetivo principal era incrementar los ingresos de los habitantes de la Zona Norte de El Salvador mediante asistencia técnica, capacitación y apoyo financiero, para generar producción de alta calidad, incrementar la pro- 
ductividad y el acceso a capital de inversión (Chemonics International, 2012a). Para el logro de tal objetivo, el PDP contó con un presupuesto de US\$87.5 millones, los cuales fueron ejecutados durante 5 años a partir de su otorgamiento, realizado el 20 de septiembre de 2007. El PDP tenía como meta beneficiar a $11 \mathrm{mil}$ personas y generar adicionalmente 9 mil empleos permanentes (Chemonics International, 2012a).

La asistencia brindada por el PDP sería a productores y empresarios de distintas cadenas de valor que se dedicasen a actividades agrícolas, agroforestales y ganaderas, y a micros, pequeñas y medianas empresas (MIPYMES) de los sectores turismo, artesanal y otros sectores no-agrícolas vinculantes. Las cadenas de valor que serían apoyadas son: cadena de valor hortofrutícola, cadena de valor lácteos, cadena de valor artesanías, cadena de valor turismo (Chemonics International, 2012a). La elección de estas cadenas de valor surgieron con base en estudios previos realizados por FOMILENIO y el Banco Multisectorial de Inversiones (BMI) como parte del proceso de formulación y aprobación del convenio entre el GOES y la MCC (SNC-Lavalin International Inc., 2008).

Durante la ejecución del PDP, distintas instituciones gubernamentales, organismos internacionales de cooperación, entre otros, han tenido conocimiento de la estrategia que el proyecto ha implementado para promover la competitividad de las cadenas de valor. El interés por conocer los detalles y actividades de la estrategia, generados en estas instituciones por el PDP, dio lugar a la gestación de un plan que incluya no solo elementos de sostenibilidad para seguir generando los beneficios logrados por el proyecto una vez finalizada la intervención de éste, sino también acciones de réplica que se basan en retomar elementos del PDP en la formulación de nuevos proyectos (Chemonics International, 2011).

\subsection{Programa de Incremento de la Competitividad de la Cadena de Valor de Turismo}

Este programa tenía como meta, para junio de 2012, posicionar a la Zona Norte como un destino turístico sostenible y competitivo, mediante la integración de actores territoriales, articulación con otros subsectores productivos y la mejora tecnológica, que se traduciría en la mejora de la calidad de los productos y servicios turísticos y la puesta en valor turístico de los recursos (Chemonics International, 2012b). Por otra parte, se destaca el hecho de que el programa turístico pretendía promover sinergias con actores de los otros programas como hortalizas, frutales, lácteos, forestales y artesanías, para proveer de insumos y productos a los prestadores de servicios turísticos (Chemonics International, 2012b) y de 
esta manera transmitir y multiplicar los logros hacia los beneficiarios de los otros programas.

En la búsqueda del cumplimiento de los objetivos del Convenio del Reto del Milenio y el PDP, el Programa de Incremento de la Competitividad de la Cadena de Valor Turismo inició operaciones el 14 de diciembre de 2010 (Chemonics International, 2011). El objetivo superior de este programa era contribuir a la generación de ingresos y empleos en el sector turismo de la zona norte, mediante la mejora en la oferta turística y la vinculación con segmentos de mercados competitivos acorde a la demanda turística (Chemonics International, 2012a).

Con relación al logro de este objetivo, FOMILENIO diseñó una estrategia turística en concordancia al Plan Nacional de Turismo 2020, en el cual se identificaron 10 polos con mayor potencial de desarrollo turístico a nivel nacional, de los cuales 4, Suchitoto en Cuscatlán, La Palma y San Ignacio en Chalatenango, Perquín en Morazán y Metapán en Santa Ana, se encuentran en la zona norte (SNC-Lavalin International Inc., 2008).

Posteriormente, se ampliaron las actividades del sub proyecto turístico para atender el municipio de Santa Rosa Guachipilín, en el departamento de Santa Ana, en vista a los beneficios que se podrían obtener aprovechando la conectividad que ofrecería la construcción de la carretera Longitudinal del Norte, financiada también con fondos del Convenio del Reto del Milenio (Chemonics International, 2011).

El Programa de Incremento de la Competitividad de la Cadena de Valor Turismo tuvo como proveedor de servicios técnicos a la Fundación para el Desarrollo Sostenible (FUNDES), institución privada sin fines de lucro -sub-contratada por Chemonics International- que tiene por misión promover la creación y el desarrollo sostenible de la micro, pequeña y mediana empresa en El Salvador (Chemonics International, 2010a). El enfoque aplicado se basaba en la integración y desarrollo de la cadena de valor turística apoyada en el desarrollo del capital social y la integración de los conglomerados turísticos, mediante el apoyo a las MYPIMES y la transferencia de tecnología que, como se ha mencionado para esta cadena, consiste en la mejora de los productos y servicios turísticos (SNC-Lavalin International Inc., 2008). De esta forma se mejora la productividad, se incrementan los ingresos y el nivel de empleos en torno a esta actividad.

En general, el Convenio del Reto del Milenio buscaba mediante su metodología que los beneficiarios fuesen los autores y actores de su propio destino, generando aprendizaje y empoderamiento en el proceso de intervención (SNC-Lavalin 
International Inc., 2008). En todo el proceso de planificación e implementación del proyecto turístico se aplicó una estrategia desde abajo, integrando a los mismos beneficiarios con el fin de que se apropien, integren y logren sentirse parte del proyecto, de manera que, al finalizar el apoyo de FOMILENIO, sus beneficios puedan ser sostenibles en el largo plazo (Chemonics International, 2011). Además, para procurar la sostenibilidad en el tiempo de las actividades, el proyecto turístico, mediante su eje transversal de medio ambiente, buscó la preservación de los recursos naturales de que disponen las zonas beneficiadas por el proyecto (Chemonics International, 2010a).

Bajo los ejes transversales de inclusión social y género, se pretendía generar oportunidades para todos los habitantes de la zona beneficiada sin distinción de género, edad o estrato social, es decir, de forma equitativa; pero recordando que la intervención iba dirigida a personas de escasos recursos y a la vez evitando la inclusión de niños en labores relacionadas con el turismo (Chemonics International, 2010a).

Según Chemonics International (2012b), para el año 2012, el Programa de Incremento de la Competitividad de la Cadena de Valor Turismo de la Zona Norte ya había atendido a 1,680 beneficiarios, ya había generado 2,203 empleos equivalentes ${ }^{2}$ y ya había incrementado los ingresos de los empresarios turísticos en un $15 \%$.

\subsection{Síntesis de apoyo de FOMILENIO al turismo de Suchitoto}

1. En dicho programa participaron 73 propietarios de hoteles, restaurantes y áreas de ecoturismo ubicados en la ciudad de Suchitoto y las comunidades La Mora y Sitio Guazapa (Chemonics International, 2010b).

2. Los empresarios recibieron asistencia técnica para mejorar la calidad de sus servicios, promoción de los mismos e identificación de oportunidades de inversión, permitiéndoles un incremento en sus ventas por más de US\$282,945.00 y generar al menos 34 nuevos empleos (Chemonics International, 2010b).

3. El Proyecto Plan de Apoyo Empresarial en Suchitoto realizó una inversión aproximada de US\$26,000.00 (Chemonics International, 2010b).

4. Apoyo al grupo de lancheros en el conocimiento de las rutas turísticas, acercamiento con tours operadores y apoyo en la adquisición de 19 toldos para lanchas valorados en US\$6,000.00 cada uno, compartiendo costos entre FOMILENIO y lancheros (Chemonics International, 2010b). 
5. Se realizaron acciones de promoción y comercialización del destino, por medio de realización de eventos, elaboración y reproducción de materiales promocionales. Entre ellos, a partir de marzo de 2010, el Puerto San Juan ya cuenta con su primer folleto promocional que contiene información de los diferentes servicios que ofrece el turicentro, como alimentación, artesanías, recorrido en lanchas y teléfonos de contactos para ampliar la información a turistas (Chemonics International, 2010c). Además, se cuenta con el desarrollo y mejoramiento de la marca turística del municipio -cuyo eslogan es "Suchitoto, más que una ciudad"-, junto a su manual para ser utilizado por los prestadores de servicios turísticos, comités y/o asociaciones de turismo (Chemonics International, 2012b). De igual forma, se llevó a cabo un evento turístico denominado "Noche Centenaria" al cual acudieron alrededor de 500 participantes. Adicionalmente, se desarrolló el concepto de "Noches Vivas", con el fin de replicarse eventualmente, en las que se han desarrollado actividades como un festival de jazz (Chemonics International, 2011).

6. Reportajes en medios de comunicación y ruedas de negocios. Por ejemplo, en mayo de 2010 se llevó a cabo una visita de periodistas de distintos medios de comunicación al Centro Turístico Puerto San Juan, donde se expusieron las iniciativas del programa, la importancia de las áreas de artesanías, turismo y frutales como generadoras de empleo e ingresos para las familias de la zona (FOMILENIO, 2010).

7. Viajes de observación con tours operadores. Uno de los Fam Trip organizados contó con la asistencia de más de 10 empresas de tours operadores, culminando con una rueda de negocios entre las operadoras y beneficiarios empresarios de la zona (Chemonics International, 2011).

8. Desarrollo de talleres de intercambio de experiencias entre las personas beneficiarias (Chemonics International, 2011).

\section{Análisis de la intervención de FOMILENIO}

Para realizar el análisis de la estrategia implementada por FOMILE$\mathrm{NIO}$ a través del programa turístico, el grupo de investigación se planteó la siguiente hipótesis a ser compro- bada: El Programa incremento de la competitividad de la cadena de valor de turismo llevado a cabo por FOMILENIO en Suchitoto propicia un proceso de desarrollo acorde 
con los cuatro componentes del paradigma de desarrollo humano. Por tanto, se pretendía verificar que las características de dicha intervención integrasen los cuatro componentes del paradigma de desarrollo humano: productividad, sostenibilidad, equidad y potenciación. A pesar de que el objetivo final del programa no fuera el desarrollo, sino el crecimiento económico, en su diseño sí se identificó la inclusión de los cuatro componentes del paradigma del desarrollo humano; además que es de suma importancia constatar si en la fase de ejecución del proyec- to, estos aspectos fueron en realidad cumplidos.

\subsection{Metodología utilizada}

Para verificar y valorar el logro de estos componentes del paradigma de desarrollo humano en el proyecto turístico de FOMILENIO, se propone la metodología de evaluación que se describe en el presente apartado. Para ello, se presentan en la tabla 3 los indicadores que se utilizarán de base en la evaluación propuesta: 


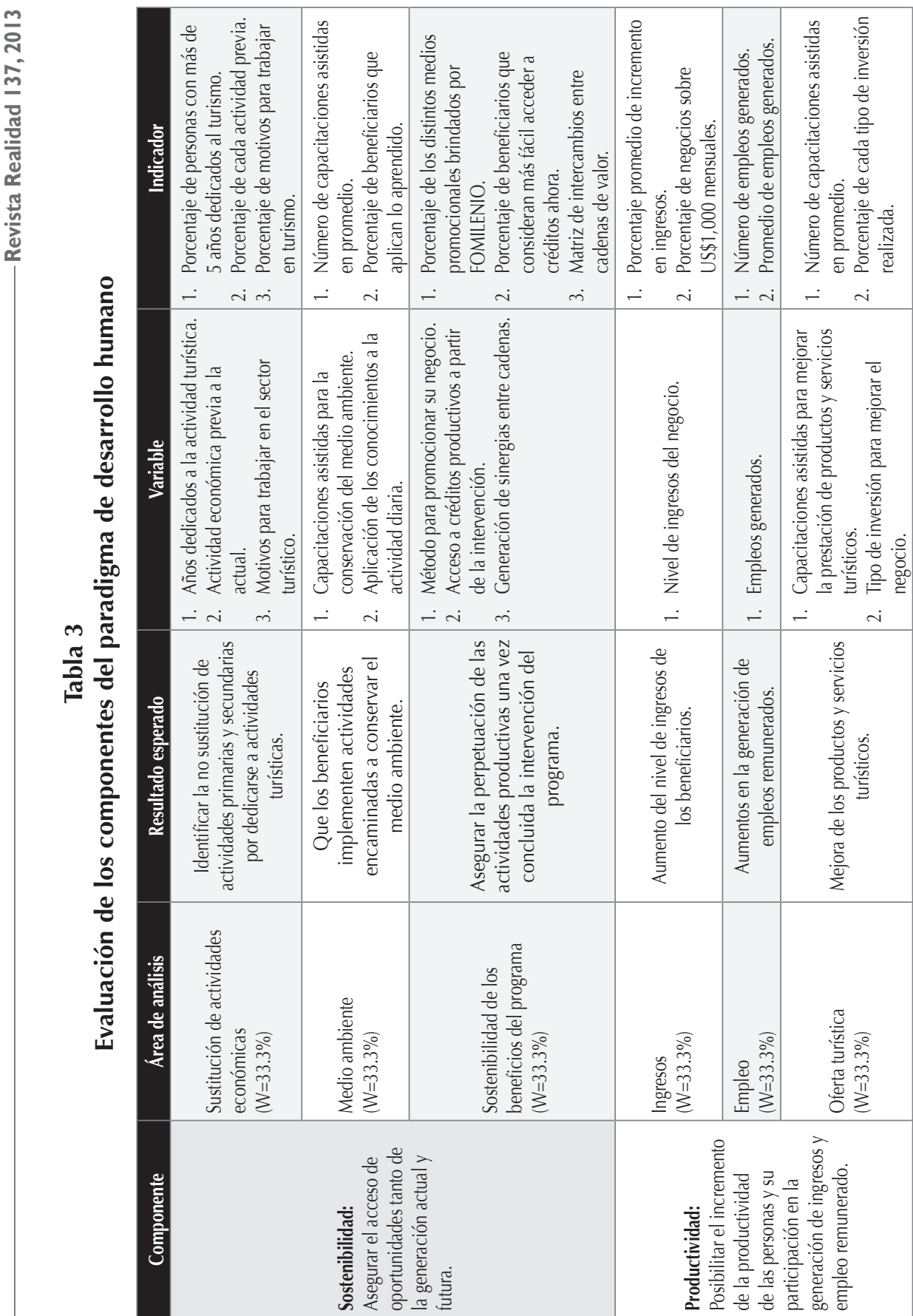




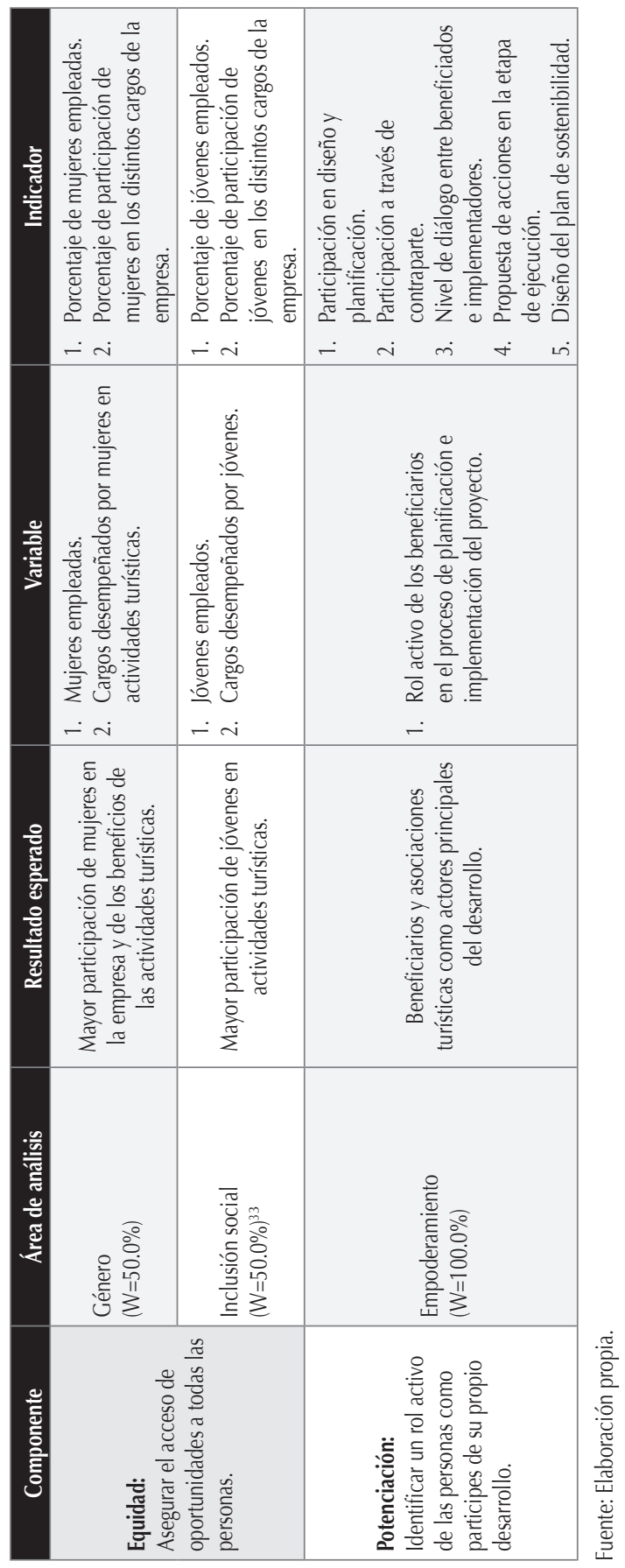


Cada una de las áreas de análisis presentadas en la tabla 3 fue ponderada a fin de obtener una calificación por cada componente del paradigma del desarrollo humano. Cada área se midió a través de una escala de valoración de 1 a 5, siendo las siguientes categorías: Muy Malo (1), Malo (2), Regular (3), Bueno (4) y Muy Bueno (5). Se aclara que se tomó a bien ponderar equitativamente las áreas de análisis que integran cada uno de los componentes del paradigma de desa- rrollo humano, ya que se consideró que dentro de los mismos, todas las áreas juegan un papel igualmente importante. Esto debido a que la búsqueda de un mejor nivel y calidad de vida requiere la integración simultánea de todos los elementos del paradigma de desarrollo humano, en función de la complejidad de las necesidades del mismo. Por lo tanto, la calificación global para cada componente se obtuvo mediante la siguiente fórmula:

Calificación global del componente $=\frac{\sum_{i}^{n}=1 X_{i} W_{i}}{\sum_{i}^{n}=1 W_{i}}$

Donde:

$\mathrm{X}_{\mathrm{i}}=$ representa la nota asignada para cada área de análisis.

$\mathrm{W}_{\mathrm{i}}=$ representa el peso respectivo de cada área de análisis.

Por otra parte, algunas de las variables presentadas en la tabla 3 se combinaron para obtener otro tipo de información, de la manera en que se presenta en la tabla 4:

\section{Tabla 4}

\section{Cruce de variables e información esperada}

\begin{tabular}{|c|l|l|l|}
\hline $\mathbf{n}^{\circ}$ & \multicolumn{2}{|c|}{ Variables a cruzar } & \multicolumn{1}{c|}{ Información esperada } \\
\hline 1 & $\begin{array}{l}\text { Actividad económica } \\
\text { previa a la actual }\end{array}$ & $\begin{array}{l}\text { Años dedicados a la } \\
\text { actividad turística }\end{array}$ & $\begin{array}{l}\text { Actividades sustituidas por el turismo en los } \\
\text { diferentes rangos de años. }\end{array}$ \\
\hline 2 & $\begin{array}{l}\text { Años dedicados a la } \\
\text { actividad turística }\end{array}$ & $\begin{array}{l}\text { Nivel de ingresos del } \\
\text { negocio }\end{array}$ & $\begin{array}{l}\text { Identificar la relación entre la antigüedad del } \\
\text { negocio y el rango de ingresos percibidos. }\end{array}$ \\
\hline 3 & $\begin{array}{l}\text { Tipo de negocio } \\
\text { Incremento de los ingresos }\end{array}$ & $\begin{array}{l}\text { Qué tipo de negocios percibió mayores } \\
\text { ingresos a partir del proyecto de FOMILENIO. }\end{array}$ \\
\hline Incremento de los & $\begin{array}{l}\text { Tipo de apoyo en publicidad } \\
\text { recibido }\end{array}$ & $\begin{array}{l}\text { Qué tipo de propaganda brindada por } \\
\text { FOMILENIO pudo haber generado mayor } \\
\text { incremento de los ingresos. }\end{array}$ \\
\hline
\end{tabular}




\begin{tabular}{|c|c|c|c|}
\hline$n^{\circ}$ & \multicolumn{2}{|c|}{ Variables a cruzar } & Información esperada \\
\hline 5 & Tipo de negocio & Empleos generados & $\begin{array}{l}\text { Qué clase de negocios turísticos generó más } \\
\text { empleos durante los últimos dos años. }\end{array}$ \\
\hline 6 & $\begin{array}{l}\text { Incremento de los } \\
\text { ingresos }\end{array}$ & $\begin{array}{l}\text { Asistencia a capacitaciones } \\
\text { impartidas por FOMILENIO }\end{array}$ & $\begin{array}{l}\text { Identificar la relación entre el incremento } \\
\text { de los ingresos de los negocios a partir de la } \\
\text { asistencia a capacitaciones impartidas por } \\
\text { FOMILENIO. }\end{array}$ \\
\hline 7 & Empleos generados & $\begin{array}{l}\text { Asistencia a capacitaciones } \\
\text { impartidas por FOMILENIO }\end{array}$ & $\begin{array}{l}\text { Identificar la relación entre la creación de } \\
\text { nuevos empleos a partir de la asistencia a } \\
\text { capacitaciones impartidas por FOMILENIO. }\end{array}$ \\
\hline 8 & Inversiones realizadas & Incremento de los ingresos & $\begin{array}{l}\text { Establecer qué tipo de inversiones realizadas } \\
\text { ha generado incrementos en los ingresos de } \\
\text { los negocios. }\end{array}$ \\
\hline 9 & Inversiones realizadas & $\begin{array}{l}\text { Asistencia a capacitaciones } \\
\text { impartidas por FOMILENIO }\end{array}$ & $\begin{array}{l}\text { Identificar la relación entre el tipo de } \\
\text { inversión realizada a partir de la asistencia a } \\
\text { capacitaciones impartidas por FOMILENIO. }\end{array}$ \\
\hline 10 & Tipo de negocio & Mujeres empleadas & $\begin{array}{l}\text { Determinar qué tipo de negocio emplea un } \\
\text { mayor número de mujeres. }\end{array}$ \\
\hline 11 & Tipo de negocio & $\begin{array}{l}\text { Empleados entre } 18 \text { y } 25 \\
\text { años de edad }\end{array}$ & $\begin{array}{l}\text { Establecer qué tipo de negocio emplea un } \\
\text { mayor número de jóvenes entre } 18 \text { y } 25 \text { años. }\end{array}$ \\
\hline
\end{tabular}

Fuente: Elaboración propia.

Para obtener los indicadores mostrados en la tabla 3, se diseñó una encuesta que capturara la información pertinente para dichos fines. ${ }^{4}$ Dicha encuesta se realizó durante el mes de junio a un total de 65 empresas representativas, ${ }^{5}$ del total de 129 beneficiadas por el proyecto turístico de FOMILENIO en Suchitoto.

Además, para obtener los datos necesarios para construir la matriz de intercambios entre cadenas de valor, mencionada en el componente de sostenibilidad, se llevaron a cabo entrevistas semi-estructuradas de la siguiente manera: a) para el proyecto frutícola, se entrevistó al coordinador del Proyecto Frutícola de FOMILENIO en Suchitoto y dos encargadas de la tienda comunitaria de la Fundación para la Cooperación y el Desarrollo Comunal de El Salvador (CORDES); b) para la cadena de valor de artesanías, se contó con la entrevista a miembros del grupo de Mujeres Artesanas Pájaro Flor; y c) para la cadena turística, se utilizó la misma encuesta realizada a los beneficiarios de empresas turísticas. Por último, para la evaluación del componente de potenciación, se llevó a cabo una entrevista estructurada al presidente de la Asociación de Desarrollo 
Turístico de Suchitoto (ADETURS) y ex alcalde del mismo municipio en el periodo de 1994 al 2006, el señor Isaías Sandoval (Morán y Ortiz, 2009: 7).

\subsection{Resultados obtenidos por componente}

A continuación se presentan los resultados obtenidos a partir de las encuestas realizadas a los beneficiarios del proyecto turístico y de las entrevistas Ilevadas a cabo, agrupados para cada uno de los componentes del paradigma de desarrollo humano $y$, al final, con la apreciación global del proyecto. ${ }^{6}$

\subsubsection{Sostenibilidad}

Las áreas de análisis de este componente se centraron en tres: sustitución de actividades económicas, medio ambiente y sostenibilidad de los beneficios del programa. Como se mostró en la tabla 3, para la evaluación de esta última área, se propuso como variable a investigar, entre otras, la generación de sinergias entre las cadenas de valor apoyadas por FOMILENIO en Suchitoto, mediante la elaboración de la matriz de intercambios, para la cual se hicieron las siguientes consideraciones: ${ }^{7}$

- Las cifras están valoradas en dólares de los Estados Unidos de Norte América y corresponden a datos mensuales. ${ }^{8}$
- El lugar que ocupan los sectores de la economía dentro de una MIP, en este caso, lo ocupan las cadenas de valor apoyadas por FOMILENIO que se seleccionaron para ser estudiadas. Cabe resaltar que se utilizó el nombre de la cadena de valor, ya que así fue llamado por el PDP y no necesariamente hace referencia al análisis individual de cada eslabón perteneciente a cada cadena.

- Los flujos que se muestran son los intercambios entre las cadenas de valor al interior del municipio y hacia el resto de la economía nacional. No se toman en cuenta exportaciones ni importaciones, es decir, intercambios con el resto del mundo.

- Se ha incluido un cuarto sector, llamado "Resto de la economía nacional", que representa la producción de bienes y servicios del resto de la economía salvadoreña que no pertenecen a ninguna de las cadenas de valor del municipio consideradas.

- La demanda final y el valor agregado (VA) de cada sector, se obtuvo por diferencia entre sus respectivos valores brutos de producción (VBP) y sus consumos intermedios totales. 
Respecto a la información necesaria para llenar las celdas de la matriz, de los 65 beneficiarios turísticos encuestados únicamente se contó con la información de 40 de ellos, ya que el restante se mostró reticente a proporcionar los datos útiles para la construcción de esta herramienta.

Además, se tomó en cuenta las cadenas de valor de artesanías y frutícola. De la cadena de artesanías, se contó con la información de un total de 15 beneficiarios de 75 que incluyó la intervención en Suchitoto; y de la cadena frutícola de un total de 627 beneficiarios del municipio, se capturó la información referente a 103 personas. En total, se capturó la información de los intercambios de aproximadamente el $22 \%$ de los beneficiarios de las tres cadenas de valor consideradas.

Para obtener la información referente al cuarto sector, se tomó como referencia la revista del Banco Central de Reserva (BCR) de El Salvador correspondiente al cuarto trimestre del año 2011:9 con ella, se obtuvo un dato aproximado del valor agregado y la demanda final mensual para todo el sistema, dividiendo el Producto Interno Bruto (PIB) anual entre doce meses. Al valor agregado mensual obtenido, se le restaron los valores agregados correspondientes a las otras cadenas de valor, y así se obtuvo el valor agregado del sector 4 .

La estimación correspondiente para el Consumo Intermedio $(\mathrm{Cl})$ del cuarto sector, se obtuvo como resultado de verificar la participación del consumo intermedio y valor agregado en el valor bruto de producción total de la economía salvadoreña durante el período comprendido de 1990 a 2006. ${ }^{10}$ Se pudo constatar que dicha participación para el consumo intermedio ha oscilado en un rango del $34 \%$ y $38 \%$ del VBP, obteniendo una media de $35.3 \%$. Para el caso del valor agregado, el rango ha sido entre el $62 \%$ y $66 \%$ del VBP, con una media de $64.5 \%$. En ambos casos, la desviación estándar ha sido de 1.2\%. Por tal motivo, al ver que dichas participaciones no han mostrado variaciones sumamente marcadas en el período considerado (17 años), se tomó para fines de la investigación la media del $\mathrm{VA}$ a fin de estimar, mediante regla de tres, el VBP del cuarto sector $y$ posteriormente su $\mathrm{Cl}$.

Tomando en cuenta lo anterior, en la tabla 5 se presenta la matriz de intercambios entre cadenas de valor: 


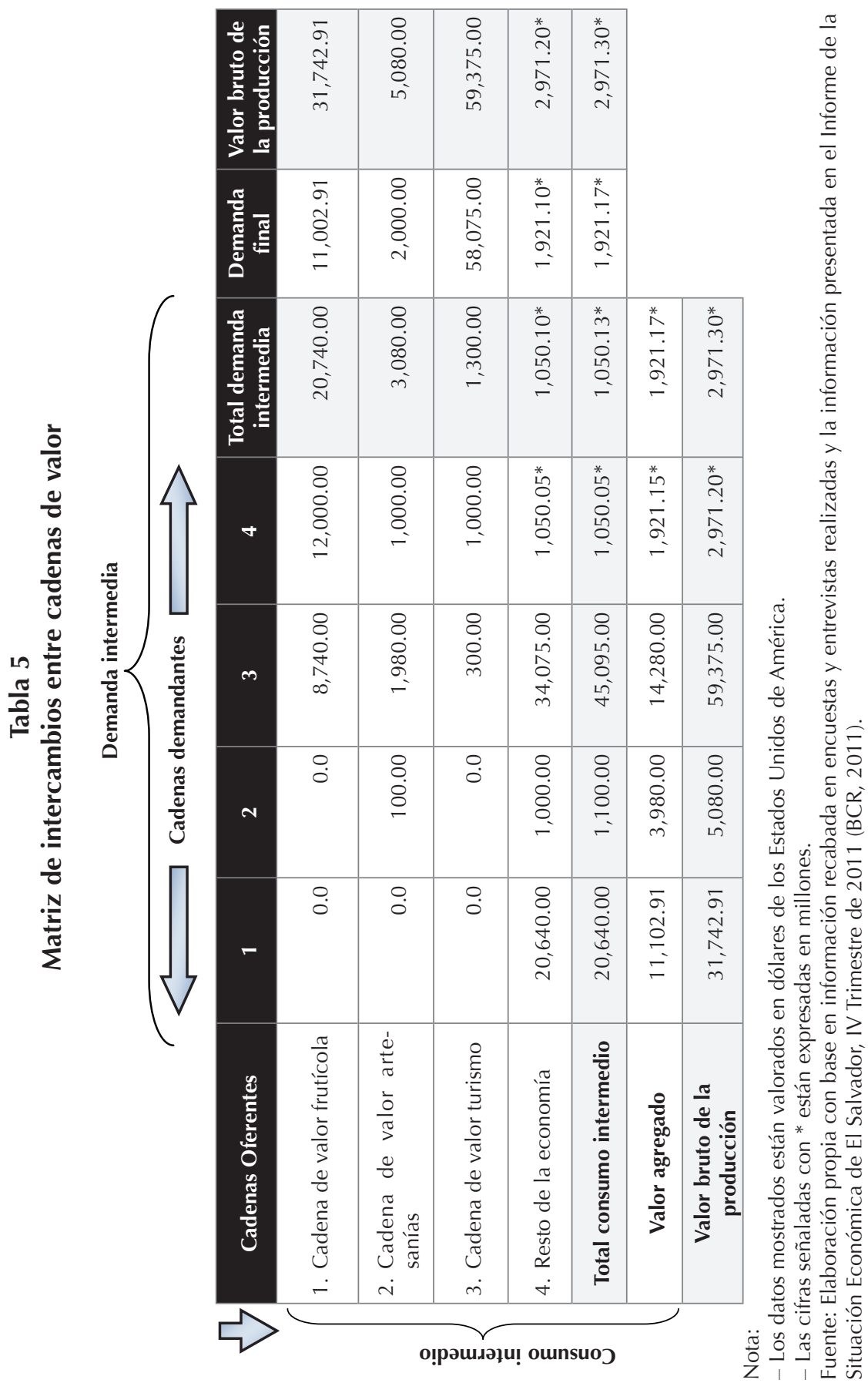


En la matriz de intercambios mostrada en la tabla 5, se observan los siguientes puntos relevantes:

- Como es de esperarse, la totalidad de insumos que demanda la cadena de valor frutícola, corresponden al sector denominado "Resto de la economía nacional", ya que ninguna cadena de valor seleccionada forma parte de los proveedores de insumos de ellos.

- Respecto a la cadena de valor de artesanías, el valor que se muestra reflejado como demanda interna a sí mismo es porque entre los mismos artesanos intercambian productos para su posterior comercialización. Los demás insumos los obtienen del resto de la economía nacional.

- Para la cadena de valor turística, se muestra que obtiene mayoritariamente insumos provenientes del resto de la economía. Sin embargo, considerando las cadenas de valor locales, la frutícola posee un volumen de oferta intermedia considerable hacia dicha cadena, en vista que la mayoría de negocios son hoteles y restaurantes. Además, fue posible observar que entre la misma cadena existe un intercambio de productos y servicios para sí mismo. Lo anterior se deriva en cuanto algunos hoteles u hostales, para poder ofrecer un mejor servicio a sus clien- tes, recurren a los restaurantes locales como proveedores de alimentos y así poder ofrecerlos a sus huéspedes.

- Asimismo, se estima que el valor agregado del sector turístico podría ser mucho mayor al mostrado en la matriz, en vista que para obtener esta información, los encuestados se mostraron muy reservados a no detallar los montos reales necesarios para calcular dicho valor agregado.

- Entre la oferta destinada a satisfacer la demanda intermedia del sector representativo del resto de la economía nacional, se observa que la cadena de valor frutícola ofrece el mayor volumen de productos. Sin embargo, se estima que ese volumen en determinados meses, sea por temporadas altas de producción o por una mayor demanda de productos frutícolas, podría incluso ser el doble del monto mostrado en la matriz.

- Como era de esperarse, el monto ofrecido por la cadena de valor turística a la demanda final es alta, rondando los US\$58,000.00 mensuales.

Lo importante de observar en este ejercicio sobre las relaciones entre las cadenas de valor apoyadas por FOMILENIO en Suchitoto, es que se ha podido vislumbrar que 
el sector turístico demanda una considerable cantidad de insumos provenientes de las otras cadenas, permitiendo crear para sus productos un mercado potencial en la localidad.

Cabe resaltar que, por motivos de tiempo e información disponible, no se incluyó en la matriz los intercambios con las cadenas de lácteos, hortalizas, acuícolas y apícolas que también han sido apoyadas por FOMILENIO en Suchitoto. A pesar de eso, se considera que el sector turístico también logra articularse con estos otros tipos de productos y servicios locales debido a la demanda que de ellos realizan los turistas.

Con el análisis realizado sobre el programa turístico de FOMILE$\mathrm{NIO}$ y las sinergias establecidas con las otras cadenas de valor apoyadas por el mismo, se ha vislumbrado que la intervención, aunque de manera indirecta, sí logró establecer un encadenamiento entre ellas. ${ }^{11}$ Esto es así ya que la actividad turística de la zona logra crear un mercado para los productos provenientes de estas otras cadenas y que le sirvan de insumo en la prestación de sus servicios. Por consiguiente, hace que la economía local se oriente hacia un auto-sostenimiento de sus actividades. De manera que, considerando la MIP y el resto de indicadores analizados para el componente de sostenibilidad, se obtuvieron los siguientes hallazgos:
- El inicio del proyecto turístico de FOMILENIO no se mostró como un incentivo para las personas a abandonar actividades económicas tradicionales por dedicarse al turismo.

- La estrategia aplicada por el PDP apoyó a otro tipo de actividades productivas en la localidad, contribuyendo a evitar dichos desplazamientos.

- El proyecto realizó acciones encaminadas a la conservación del lago Suchitlán, pero aparte de eso no hizo mucho por la conservación general del medio ambiente de la localidad.

- El proyecto facilitó la propaganda suficiente para dar a conocer a los negocios individualmente, así como al municipio como destino turístico.

- El proyecto facilitó un acercamiento entre instituciones financieras y beneficiarios; sin embargo, no brindó una asistencia que contribuyera a que los beneficiarios de los sectores más pobres accedieran a préstamos de manera más fácil.

- No se pudo corroborar que en el sector turístico de Suchitoto existiera algún proyecto de inversión que estuviera siendo apoyado por la actividad del 
PDP destinada a ofrecer servicios de apoyo a la inversión.

El proyecto turístico sí logró crear sinergias, al menos de manera indirecta, con otras cadenas de valor apoyadas por FOMILENIO, aunque éstas aún son débiles, como se pudo constatar con el ejercicio de la MIP realizado.

Por lo tanto, la calificación obtenida para las distintas áreas de análisis del componente de sostenibilidad se presenta en la tabla 6:

\section{Tabla 6}

\section{Calificación de áreas de análisis (sostenibilidad)}

\begin{tabular}{|c|c|c|}
\hline Área de análisis & Calificación & Global componente \\
\hline Sustitución de actividades económicas & 4.33 & \multirow{2}{*}{3.6} \\
\hline Medio ambiente & 3.33 & \\
\hline Sostenibilidad de los beneficios del programa & 3 & \\
\hline
\end{tabular}

Fuente: Elaboración propia con base en la percepción del grupo sobre el desempeño de las áreas de análisis en cuestión.

Como se muestra en la tabla 6, el grupo de investigación considera que el programa de apoyo a la actividad turística de FOMILENIO, en cuanto al eje de sostenibilidad, tuvo una calificación de 3.6, lo que implica un desempeño regular tendiendo a bueno, ya que contribuyó a no crear una terciarización de la economía local, a encaminar algunos esfuerzos tendientes a conservar el medio ambiente y a que los empresarios pudiesen mantener los beneficios del proyecto, una vez éste termine su intervención. Sin embargo, se considera que algunos aspectos en torno a la conservación del medio ambiente, acceso a capital de inversión y los esfuerzos realizados en la generación y fortalecimiento de las sinergias entre cadenas, debieron ser aún más fuertes para garantizar un proceso de desarrollo que sea capaz de perdurar en el tiempo.

\subsubsection{Productividad}

El análisis para este componente se centró en las áreas de ingresos, empleo y oferta turística; de las cuales se obtuvieron los siguientes resultados:

- El proyecto sí logro incrementar los ingresos de la mayoría de los negocios beneficiados, aunque un porcentaje casi igual de los mismos considera que no han experimentado mejoras a partir de la ayuda recibida.

- Las capacitaciones impartidas por el proyecto para mejorar la 
oferta turística han sido determinantes en el incremento de la generación de ingresos de los negocios, no obstante, las inversiones realizadas no generaron tal efecto en los mismos. Esto último resultó ser lo opuesto a lo esperado por el proyecto.

- Gracias a los beneficios generados por el proyecto, como el aumento de clientes e ingresos en los negocios, se ha creado, en promedio, por lo menos un empleo nuevo por negocio encuestado en los últimos dos años.

- Los beneficiarios reconocen que solo el $5 \%$ de las inversiones realizadas en los negocios durante la ejecución del proyecto han sido producto directo de FOMILENIO.

Por lo anterior, la calificación obtenida para las distintas áreas de análisis del componente de productividad se presenta en la tabla 7 :

Tabla 7

Calificación de áreas de análisis (productividad)

\begin{tabular}{|c|c|c|}
\hline Área de análisis & Calificación & Global componente \\
\hline Ingresos & 4.0 & \multirow{2}{*}{3.9} \\
\hline Empleo & 4.0 & \\
\hline Oferta turística & 3.67 & \\
\hline
\end{tabular}

Fuente: Elaboración propia con base en la percepción del grupo sobre el desempeño de las áreas de análisis en cuestión.

Como se muestra en la tabla 7 , se piensa que el proyecto logró una calificación de 3.9 en el componente de productividad, lo que denota un desempeño cercano a bueno, ya que incidió en el incremento de los ingresos de los negocios beneficiados, mediante la potenciación de la productividad de los mismos a través de, en su mayoría, capacitaciones relacionadas a la mejora de la oferta turística.

A su vez, esto generó dinámicas que crearon nuevos empleos en los distintos negocios, pues la expansión de servicios y mejora de productos implicó la creación de nuevas plazas. A pesar de lo anterior, el apoyo a nuevas inversiones por parte de FOMILENIO a los beneficiados no tuvo mayor relevancia, ya que el porcentaje de participación directa en éstas no fue significativo.

\subsubsection{Equidad}

En este tema, el estudio se centró en el área de género e inclusión social, de las cuales se pudo obtener los siguientes resultados: 
- Respecto al tema de género, la mayoría de personas empleadas en los negocios turísticos de Suchitoto son mujeres, aunque su participación en dichos negocios es subordinada, pues la gran mayoría no ocupa cargos que impliquen toma de decisiones.
- En cuanto al eje transversal de inclusión social, se ha logrado que el $28 \%$ de los empleados de negocios turísticos de Suchitoto sean personas con edades entre los 18 y 25 años.

Por lo anterior, la calificación obtenida para las distintas áreas de análisis del componente de equidad se presenta en la tabla 8 :

Tabla 8

Calificación de áreas de análisis (equidad)

\begin{tabular}{|c|c|c|}
\hline Área de análisis & Calificación & Global componente \\
\hline Género & 3.0 & \multirow{2}{*}{3.2} \\
\hline Inclusión social & 3.33 & \\
\hline
\end{tabular}

Fuente: Elaboración propia con base en la percepción del grupo sobre el desempeño de las áreas de análisis en cuestión.

Como se muestra en la tabla 8 , se concluye que el proyecto turístico de FOMILENIO ha tenido una calificación de 3.2 en el componente de equidad, lo que denota un desempeño regular, ya que a pesar de que generó oportunidades de acceso al mercado laboral a mujeres y jóvenes, no se logró que hombres y mujeres ocuparan cargos en los negocios que implicasen toma de decisiones en proporciones similares.

\subsubsection{Potenciación}

Este componente se basó en cinco aspectos importantes a evaluar con el fin de analizar el nivel de empoderamiento que han tenido los beneficiarios del proyecto. Estos son:
- La participación de los beneficiarios en los procesos de diseño y planificación del proyecto.

- La participación de los beneficiarios en el desarrollo de las distintas actividades y beneficios del proyecto a través del aporte de contrapartes.

- El nivel de diálogo que existe entre los beneficiarios y el personal encargado de administrar y ejecutar el proyecto.

- La concesión de oportunidades a los beneficiarios de proponer ideas sobre acciones que pueda realizar el proyecto para potencializar el turismo del municipio y a la vez si dichas 
propuestas han sido tomadas en cuenta y realizadas.

- El nivel de cooperación entre beneficiarios y personal responsable de la ejecución del proyecto en el diseño de un plan de sostenibilidad de los beneficios logrados por el proyecto.

Los resultados obtenidos se pueden resumir de la siguiente manera:

- A pesar de que los beneficiarios participaron en la etapa de consulta para el diseño y planificación de la intervención que realizaría FOMILENIO, a juicio de los mismos beneficiarios, las propuestas realizadas no fueron consideradas en su totalidad pues no fueron incluidas en el plan final.

- Los encargados de la intervención se mostraron receptivos a escuchar las propuestas realizadas por los beneficiarios durante la etapa de ejecución del proyecto, e incluso algunas fueron realizadas.

- No existió un mecanismo de retroalimentación entre beneficiarios y ejecutores que contribuyera a fortalecer el diseño original del plan.

- La contrapartida exigida a los beneficiarios, al no incluir elementos materiales como dinero o especie, no fue tal que pudiera contribuir a generar un sentido de pertenencia en los mismos sobre los logros alcanzados por el proyecto.

- A su vez, dado que la contrapartida sí consistió en asuntos de logística, sí pudo haber generado un aprendizaje que permita que los beneficiarios del proyecto puedan ejecutar sus propias iniciativas, como organización de eventos que contribuyan a la promoción del municipio y que impliquen acuerdo y cooperación entre los empresarios de la localidad, una vez finalice el proyecto.

- Los beneficiarios no consideran necesario crear un plan de sostenibilidad de los beneficios del proyecto para cuando termine, debido a que éste no llenó sus expectativas, pues esperaban ser apoyados en financiamiento y no en capacitaciones sobre la mejora de los servicios que ofrecen; de manera que no hubo una concordancia entre lo que los beneficiarios deseaban recibir con la ayuda que el proyecto pretendía brindar.

Por lo anterior, la calificación obtenida para las distintas áreas de análisis del componente de potenciación se presenta en la tabla 9: 
Tabla 9:

Calificación de área de análisis (potenciación)

\section{Área de análisis}

Empoderamiento
Calificación

2.67
Global componente

2.7

Fuente: Elaboración propia con base en la percepción del grupo sobre el desempeño del área de análisis en cuestión.

Como se muestra en la tabla 9 , se concluye que el desempeño del proyecto turístico de FOMILENIO ejecutado en Suchitoto, respecto al componente de potenciación, tiene una calificación de 2.7, considerándose como malo tendiendo a regular, por lo que de los cuatro componentes del paradigma de desarrollo humano es en el que más trabajo les restó por hacer: los beneficiarios no jugaron un rol determinante en el proceso de planificación del proyecto y esto generó en ellos una sensación de "desánimo" en la etapa de ejecución de la intervención.
En general, durante todas las etapas del proyecto, los beneficiarios tuvieron una participación limitada y no participaron activamente en las tomas de decisiones. Para el caso particular de FOMILENIO, lo anterior es especialmente grave, dado que se ha mencionado que un factor básico de la metodología aplicada por el Convenio del Reto del Milenio es que los beneficiarios sean los principales autores y actores de su propio desarrollo.

\subsection{Desempeño general del proyecto}

\section{Figura 1 \\ Desempeño general del proyecto}

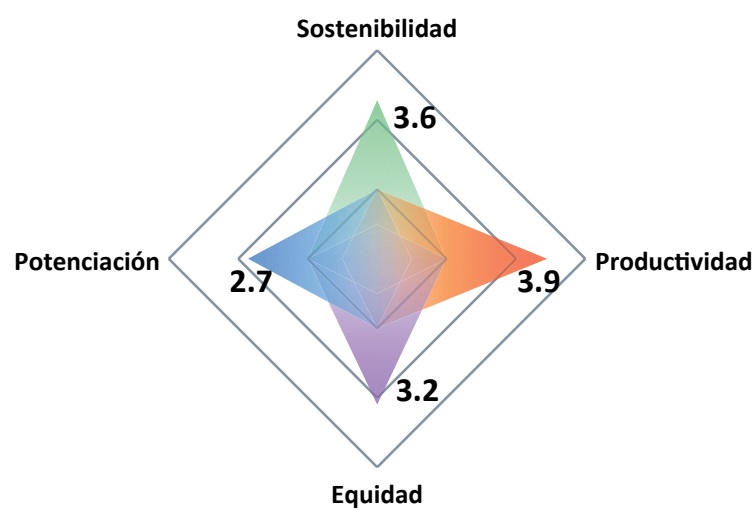

Fuente: Elaboración propia. 
Con base en lo que se muestra en la figura 1, la cual resume lo que se ha venido concluyendo en cada uno de los componentes, el grupo de investigación presenta la apreciación general sobre el Programa de Incremento de la Competitividad de la Cadena de Valor de Turismo Ilevado a cabo por FOMILENIO en Suchitoto, en el cumplimiento de los cuatro componentes del paradigma del desarrollo humano (sostenibilidad, productividad, potenciación y equidad). El perímetro externo marca una situación ideal en el cumplimiento de cada componente, mientras que el centro de la figura marca la situación opuesta.

Para el caso, es de apreciar que para los componentes de productividad y sostenibilidad, se considera que el proyecto logró abarcar las características esenciales que debe incluir un proceso de desarrollo basado en el paradigma del desarrollo humano expuesto en la investigación. Sin embargo, como se hizo notar en las conclusiones de cada componente, a la vez se considera que hubo algunos detalles de estos dos en los que su desempeño pudo ser aún mejor para lograr un mayor incremento de los ingresos y el empleo, así como asegurar aún más la permanencia de los beneficios del proyecto en el tiempo.

Por otro lado, respecto al desempeño de la intervención realizada en el componente de equidad, si bien es relativamente menor a los componentes anteriores, sí se identificaron las bases para asegurar el acceso a oportunidades de desarrollo a todas las personas por igual, sin distinción de sexo y/o edad, ya que al menos se les facilitó acceder a un trabajo que les permita obtener los ingresos necesarios para el logro de dicho desarrollo. No obstante, aún queda trabajo por hacer, en el sentido que las mujeres ostenten cargos de decisión dentro de las empresas turísticas de la localidad.

Finalmente, para el componente de potenciación, se reconoce que al proyecto le restó camino por recorrer en la inclusión de líneas guías en el diseño original del mismo que procurase una participación más activa de los beneficiarios en la planificación, ejecución, evaluación y sostenibilidad de los beneficios derivados del proyecto. Es de suma importancia que proyectos que buscan un desarrollo en general destinen un buen porcentaje de sus esfuerzos y recursos en el buen desempeño de este componente, para que la intervención no represente una asistencia paternalista más que únicamente genera beneficios mientras su duración.

Por tanto, si bien el Programa de Incremento de la Competitividad de la Cadena de Valor de Turismo llevado a cabo por FOMILENIO en Suchitoto no tuvo un desempeño bueno en ninguno de los cuatro componentes del paradigma de desarrollo humano, sí estableció 
la base para el inicio de un proceso de desarrollo acorde a dicho paradigma que permita ampliar las opciones de que disponen los hombres y mujeres del municipio de generaciones presentes y futuras.

Además, el grupo de investigación consideró conocer la opinión de los mismos beneficiarios de Suchitoto respecto al impacto que el proyecto turístico de FOMILENIO pudo haber tenido en su desarrollo. Los resultados obtenidos con dicha interrogante mostraron que un $70 \%$ de los encuestados opina que el proyecto turístico de FOMILENIO en Suchitoto sí contribuyó al desarrollo del municipio, principalmente por las siguientes razones: porque generó más oportunidades de trabajo para las personas, porque contribuyó con el trabajo que las personas del municipio realizan, porque gracias a las capacitaciones que los empleados recibieron pudieron aumentar sus ingresos, por las oportunidades de aprendizaje que generaron y por la publicidad que se les dio a los negocios y al municipio en general.

El 30\% restante de los encuestados opina que el proyecto no contribuyó con el desarrollo del municipio por diversas razones, entre ellas: porque consideran que el apoyo no se le concedió a la mayoría de personas, porque hubieran preferido que el proyecto consistiera más en donación de fondos en efectivo no reembolsables o acceso a créditos blandos para invertir en los negocios, porque el acceso a vivienda y la vida para los habitantes locales se ha encarecido a raíz de la afluencia de los turistas, porque consideran que la comunidad en general no se beneficia de la ayuda brindada a los negocios.

De manera que, aunque la mayoría de encuestados opinan que el proyecto sí tuvo una influencia positiva en su desarrollo, sin duda el hecho de que el desempeño del mismo no haya sido igualmente aceptable en los cuatro componentes del paradigma de desarrollo humano contribuye a que algunas de estas personas tengan una percepción nula o incluso negativa al respecto. Por lo que se vuelve necesario aplicar medidas en futuros proyectos que corrijan las falencias que se tuvieron en éste y que a la vez fortalezcan los aspectos positivos que sí se lograron, con el fin de lograr establecer definitivamente un proceso de desarrollo rural que permita mejorar las vidas de muchas generaciones de los habitantes de Suchitoto.

\section{Conclusiones y recomendaciones}

El municipio de Suchitoto integra muchos elementos presentes en el concepto de ruralidad propuesto en la investigación aquí resumida: es una zona en la que confluyen actividades agrícolas, turísticas, culturales y religiosas a través de las cuales se interrelacionan sus 
pobladores. Es un lugar con una identidad histórica y cultural muy arraigada entre sus habitantes, posee una riqueza natural de amplio reconocimiento para actividades turísticas y que propicia el desarrollo de actividades productivas acorde al medio.

Con relación al proyecto turístico de FOMILENIO, se constató que éste logró trabajar sobre una realidad específica, sin trastocar las actividades que históricamente se venían realizando en Suchitoto, en ámbitos económicos, culturales, sociales, entre otros. Es decir, las interrelaciones existentes entre los pobladores en las diversas esferas citadas no fueron producto de la implementación del proyecto, sino que son resultado de un proceso de organización histórica y territorial del municipio previo al mismo, lo cual también es acorde con el concepto de ruralidad propuesto.

Se evidenció que efectivamente en Suchitoto se ha planificado e implementado una estrategia de desarrollo que aprovecha de forma eficaz las ventajas naturales que ofrece el municipio, lo cual es acorde a las ideas de la nueva ruralidad planteadas por el IICA.

Además, se encontró que a pesar del apoyo brindado por la municipalidad hacia actividades turísticas, esto no es un incentivo para dedicarse a ellas en Suchitoto; sin embargo, se constató que el proyecto de FOMILENIO supo valerse de la capacidad organizativa e influencia de las instituciones formales e informales ya establecidas previamente en la localidad. Esto se relaciona con el elemento de reforma de la nueva ruralidad planteada por el IICA y con el cumplimiento de la meta del programa de integrar en el transcurso del mismo a los actores de la localidad.

Por otro lado, de acuerdo a lo planteado por aquellos que defienden el "nuevo paradigma del desarrollo rural", el turismo sí representa una alternativa viable para el desarrollo sostenible de Suchitoto, pues es una actividad complementaria a las actividades agrarias del municipio, siendo así un dinamizador de la economía local; esto se evidencia gracias al ejercicio de la MIP realizado sobre los intercambios entre cadenas productivas apoyadas por FOMILENIO en Suchitoto.

Retomando esta última idea, también se confirmó que el turismo logra lo recomendado por la CEPAL: que las actividades nuevas generen demanda en las actividades productivas tradicionales y a la vez que ofrezcan posibilidades para desarrollar otras actividades.

Aunque no se identifiquen los componentes del paradigma de desarrollo humano directamente en el planteamiento del proyecto turístico de FOMILENIO, éste sí contiene elementos que contribuyen 
a generar un proceso de desarrollo conforme a dicho paradigma.

Respecto al desempeño del proyecto de FOMILENIO y a los ya mencionados componentes del paradigma de desarrollo humano, se destacan las siguientes conclusiones:

- El proyecto turístico de FOMILENIO no contribuyó a terciarizar la economía de Suchitoto.

- La intervención de FOMILENIO realizó actividades que propiciaron la conservación y el buen uso del lago Suchitlán, el cual es determinante para la sostenibilidad de la actividad turística del municipio; sin embargo, no invirtió esfuerzos en la conservación de otros elementos del medio ambiente local.

- Respecto al componente de sostenibilidad, los esfuerzos no fueron lo suficientemente fuertes como para asegurar un proceso de desarrollo perdurable en el tiempo.

- Mediante el ejercicio práctico de la MIP, se identificaron las bases para el fortalecimiento de la economía local. No obstante, aún existe una dependencia considerable respecto al aprovisionamiento de insumos por el resto de la economía nacional. El fortalecimiento de estos encadenamientos es esencial para la transmisión de los beneficios que eviten desplazamientos de actividades que generen la terciarización de la economía local.

- El proyecto generó un incremento de ingresos y creó empleos a través del apoyo brindado para mejorar la oferta de las empresas turísticas de Suchitoto. Empero, se encontró que los esfuerzos realizados directamente por el proyecto en la mejora de acceso a recursos para inversiones no fueron determinantes para el logro completo de los objetivos que el PDP se había planteado.

- Gracias a las capacitaciones brindadas por el proyecto turístico de FOMILENIO, se logró mejorar la gestión empresarial de las MIPYMES turísticas de Suchitoto.

- El apoyo brindado por el proyecto a los empresarios en términos de publicidad mejoró su acceso al mercado, ya que contribuyó a fortalecer su posición como destinos turísticos sostenibles y competitivos.

- El proyecto turístico de FOMILENIO logró abrir nuevas oportunidades de empleo a mujeres y jóvenes; sin embargo, respecto al tipo de participación que tienen estos segmentos pobla- 
cionales en el sector turismo, faltaron mayores esfuerzos para lograr su plena integración, pues la mayoría no ostenta cargos que impliquen tomas de decisiones.

- El eje transversal de inclusión social considerado por el proyecto turístico de FOMILENIO se redujo a la consideración de jóvenes, dejando de fuera a otras áreas de la población en riesgo de exclusión, como por ejemplo personas discapacitadas.

- Sí se intentó implementar una estrategia desde abajo en el desarrollo del programa, pero la no concordancia entre los objetivos de éste y las expectativas de ayuda de los beneficiarios, obstaculizó el logro completo de tal estrategia.

- El componente de productividad fue el mejor evaluado, ya que los objetivos del proyecto están en sintonía directa con éste. A pesar de ello, el desempeño del proyecto en los componentes de sostenibilidad y equidad ha sido aceptable para sentar la base de un incipiente proceso de desarrollo sostenible.

- Las deficiencias en el desempeño del proyecto respecto a los cuatro componentes del paradigma de desarrollo humano generaron que algunos beneficiarios tuviesen percepciones nulas o incluso negativas de la intervención.

Para futuros proyectos que busquen propiciar un proceso de desarrollo sostenible basado en el paradigma del desarrollo humano y para mantener los beneficios logrados por el proyecto turístico de FOMILENIO, se plantean las siguientes recomendaciones:

- La implementación de proyectos en áreas rurales que se basen en el paradigma de desarrollo humano deben de tomar en cuenta los rasgos intrínsecos de los territorios y potencializarlos. Deben proponerse influenciar las distintas esferas en que se interrelacionan las poblaciones, ya que son éstas las que le dan forma a los territorios rurales, tal como se define en el concepto de ruralidad propuesto en la investigación.

- Los apoyos productivos deben realizar esfuerzos conjuntos en las cadenas claves que se desarrollan en los territorios objetivo, esto para evitar sustituciones de actividades no beneficiadas por otras que sí lo sean.

- Se propone realizar el análisis de las relaciones sociales de producción establecidas al interior de iniciativas productivas, 
ya que la información provista por éste, como la forma en que se distribuye el ingreso, por ejemplo, puede ser de mucha utilidad al momento de diseñar proyectos y evaluar los impactos causados por los mismos.

- Dentro de la formulación de proyectos, se deben establecer mecanismos que velen por la aplicación de lo aprendido en las capacitaciones recibidas.

- Proveer durante el desarrollo del proyecto medios y recursos necesarios para facilitar el acceso a segmentos de mercados competitivos a MIPYMES beneficiadas.

- Se deben crear mecanismos adecuados para facilitar el financiamiento de las MIPYMES, ya sea a través de la concesión de créditos blandos o de desembolsos en efectivo no reembolsables, solicitando en este caso contrapartes acordes a la capacidad del beneficiario.

- Con la MIP se pueden desarrollar proyectos que busquen crear o verificar encadenamientos productivos en las localidades. Para el caso específico analizado en el municipio de Suchitoto, se deben realizar esfuerzos para mantener $y / 0$ mejorar las relaciones logradas entre ellas.
- El diseño de una MIP, al momento de plantear una línea base en el desarrollo de proyectos, puede ser utilizado como herramienta para identificar las áreas en las que se requiera focalizar mayor intervención. También puede ser comparada con otra al final del proyecto, para cuantificar el avance obtenido.

- Se puede recurrir al uso de la MIP en la planificación de políticas y/o proyectos que busquen fortalecer las relaciones inter e intra sectoriales de las localidades.

- Impartir capacitaciones como estrategia para la mejora de la gestión empresarial y de la oferta de las MIPYMES, pues se ha evidenciado que son determinantes en el incremento de ingresos de los negocios.

- El incremento de ingresos generados por los beneficiarios del proyecto de FOMILENIO deben ser reinvertidos en mejoras a la empresa que le permitan ganar más y nuevos segmentos de mercados.

- Se deben adoptar medidas para permitir oportunidades laborales a mujeres y jóvenes, que son los sectores de la población con más dificultades de acceso a trabajo. 
- Al formular proyectos, aparte de la inversión en capacitaciones que mejoren las habilidades de las mujeres, se deben incluir actividades que concienticen sobre la equidad de género a los beneficiarios.
- En la implementación de un proyecto es fundamental involucrar a los beneficiarios en todas las etapas, para que sientan que han contribuido en los logros alcanzados, creando en ellos una actitud que busque la conservación de los beneficios una vez el proyecto haya terminado.

\section{Bibliografía}

os Amaya, M.; Arteaga, K.; Gámez, A. y S. Olivares, (2010) Impacto de las Políticas Públicas en el Desarrollo Rural de El Salvador. Período 19922008. Tesis de licenciatura en economía. Antiguo Cuscatlán: Departamento de Economía, Facultad de Ciencias Económicas y Empresariales, Universidad Centroamericana "José Simeón Cañas".

os BCR, (2011) "Informe de la Situación Económica de El Salvador, IV Trimestre de 2011" en Informe de Situación Económica [En Línea]. El Salvador, disponible en: http://www.bcr.gob.sv/esp/index.php?option=com_ wrapper\&view=wrapper\&Itemid $=308$

os Bringas, O., (2008) "El Turismo Rural" en Revista Universidad de Sonora [En Línea] No. 21. Abril-Junio 2008, Universidad de Sonora, disponible en: http://www.revistauniversidad.uson.mx/revistas/21-El\%20turismo\%20 rural.pdf

os CEPAL, (2005) "Serie - Estudios Estadísticos y Prospectivos №37: Tópicos sobre el Modelo de Insumo-Producto; teoría y aplicaciones" en División de Estadística y Proyecciones/Publicaciones y Documentos/CEPAL [En Línea]. Chile, disponible en: http://www.cepal.org/cgi-bin/getprod. asp?xml=/deype/noticias/paginas/9/39579/P39579.xml\&xsl=/deype/tpl/ p18f.xsl\&base=/deype/tpl/top-bottom.xsl

os CEPAL, (2011) "Macroeconomía para el Desarrollo: Políticas Anticíclicas y Transformación Productiva", en Revista 104, Comisión Económica para América Latina y el Caribe, Agosto 2011.

os Chalabi, N., (2009) "Turismo Rural (TR) en El Salvador Recopilación de Información Institucional", San Salvador: Instituto Interamericano de Cooperación para la Agricultura (IICA).

os Chemonics International, (2010a) "Fortalecimiento de las MIPYMES turísticas de la zona norte, mediante la mejora de la oferta turística 
y de los mecanismos de promoción y comercialización" en Servicios de Producción y Negocios-FOMILENIO-Chemonics International [En Línea]. El Salvador, disponible en: http://www.pdpfomilenio.org/main. php?c $=1 \&$ id $=190 \& s=4$

os Chemonics International, (2010b) "Servicios de Producción y Negocios. Presencia en Municipios del Departamento de San Salvador y Cuscatlán" en Servicios de Producción y Negocios-FOMILENIO-Chemonics International [En Línea]. El Salvador, disponible en: http://www.pdpfomilenio.org/main.php?id=89\&s=4

os Chemonics International, (2010c) "Chemonics Informa" en Centro de Noticias - Proyecto de Desarrollo Productivo- Fomilenio [En Línea]. Boletín N8, Marzo 2010, El Salvador, disponible en: http://www.pdpfomilenio.org/main.php?c=1\&id=95\&s=4

os Chemonics International, (2011) "Informe Anual III Año, 17 de septiembre de 2010 al 14 de septiembre 2011" en Servicios de Producción y Negocios-FOMILENIO-Chemonics International [En Línea]. El Salvador, disponible en: http://www.pdpfomilenio.org/main.php?page $=0 \& s=6$

os Chemonics International, (2012a) "Manual de Procedimientos para la Ejecución de Iniciativas Productivas" en Servicios de Producción y Negocios-FOMILENIO-Chemonics International [En Línea]. El Salvador, disponible en: http://www.pdpfomilenio.org/main.php?s=6\&id=10

os Chemonics International, (2012b) "Programa de Incremento de la Competitividad de la Cadena de Valor de Turismo de la Zona Norte" en Servicios de Producción y Negocios-FOMILENIO-Chemonics International [En Línea]. El Salvador, disponible en: http://www.pdpfomilenio.org/ main.php?c $=14 \&$ id $=31 \& \mathrm{~s}=8 \& \mathrm{c}=14$

os Chiang, A., (1984) Fundamental Methods of Mathematical Economics, Third Edition, McGraw-Hill.

os Escobar, C., (2006) La Matriz Insumo-Producto como instrumento de planificación del desarrollo económico en comunidades organizadas de los países pobres: el caso del Grupo Bajo Lempa en El Salvador. Tesina preparada para el master en Desarrollo Económico. Madrid: Universidad Carlos III de Madrid.

os FOMILENIO, (2010) "Periodistas Evidencian Apoyo en Suchitoto" en Centro de Noticias - Proyecto de Desarrollo Productivo- Fomilenio [En Línea]. El Salvador, disponible en: http://www.pdpfomilenio.org/main. php?c=16\&id=107\&s=4 
os FOMILENIO. (2012a) "¿Qué es la MCC?" en FOMILENIO. [En Línea]. El Salvador, disponible en: http://www.mca.gob.sv/wfContenidoGenerico. asp ? codigo $=9215$

os FOMILENIO. (2012b) "Antecedentes" en FOMILENIO. [En Línea]. El Salvador, disponible en: http://www.mca.gob.sv/wfContenidoGenerico. aspx? codigo $=13662$

os FUSADES, (1999) "Crecimiento con Participación: Una Estrategia de Desarrollo Para el Siglo XXI" en Departamento de Estudios Económicos y Sociales/ FUSADES [En Línea]. El Salvador, disponible en: http:// www.fusades.org/index.php?cat=1231\&lang=es\&title=Estrategias $\% 20$ Quinqenales

os GOES, (2008) "VI Censo de Población y V de Vivienda 2007", [En Línea]. El Salvador, disponible en: http://www.censos.gob.sv/util/datos/ Resultados\%20VI\%20Censo\%20de\%20Poblaci\%F3n\%20V\%20de\%20 Vivienda\%202007.pdf

os GOES-MCC, (2006) "Convenio del Reto del Milenio" en FOMILENIO [En Línea]. Washington D.C., disponible en: http://www.mca.gob.sv/ contenidolmagen.ash $x$ ?codigo $=420 \&$ tipo $=2$

os Gómez, I. y X. Ortíz, (2010) La apuesta por un turismo sostenible en El Salvador: Propuestas para un cambio de políticas, Programa Salvadoreño de Investigación sobre Desarrollo y Medio Ambiente, San Salvador.

os Gutiérrez, E. (2007) "De las Teorías del Desarrollo al Desarrollo Sustentable. Historia de la Construcción de un Enfoque Multidisciplinario" en Sistema de Información Científica - Redalyc [En Línea]. México, disponible en: http://redalyc.uaemex.mx/src/inicio/ArtPdfRed. jsp?iCve $=60715120006$

os Herrera, J. (2012) "Desarrollo Rural con Enfoque Territorial" en Publicaciones y Documentos-I/CA [En Línea]. El Salvador, disponible en: http:// www.iica.int/Esp/regiones/central/salvador/Documents/articulo_1.pdf

os IICA, (2000). "Nueva Ruralidad", en IICA. [En línea]. Panamá, disponible en: http://bibliotecavirtual.clacso.org.ar/ar/libros/rjave/paneles/urra.pdf

cos Juárez, J. P. y B. Ramírez, (2007) "El turismo rural como complemento al desarrollo territorial rural en zonas indígenas de México" en Scripta Nova. Revista Electrónica de Geografía y Ciencias Sociales [En Línea] Vol. XI, núm. 236. Abril 2007, Universidad de Barcelona, disponible en: http://www.ub.es/geocrit/sn/sn-236.htm

os MCC. (2012a) "About MCC" en Millennium Challenge Corporation. [En línea]. Estados Unidos, disponible en: http://www.mcc.gov/pages/about 
os MCC. (2012b) "El Salvador Compact" en Millennium Challenge Corporation. [En línea]. Estados Unidos, disponible en: http://www.mcc.gov/ pages/countries/program/el-salvador-compact

os Ministerio de Gobernación de El Salvador, (2007) Diario Oficial, Tomo No. 374, número 2. San Salvador, jueves 4 de enero de 2007.

os Montero, I. (2006) "La Cuenta para el Desafío del Milenio: de la teoría a la práctica" en Real Instituto Elcano [En Línea]. Madrid, disponible en: http://ribei.org/983/1/ARI-26-2006-E.pdf

os Morán, W. y X. Ortíz, (2009) "Turismo, ¿Una Alternativa para Quien? Estudio de Caso en Suchitoto" en Archivos de PRISMA [En Línea]. El Salvador, disponible en: http://www.prisma.org.sv/uploads/media/suchitoto.pdf

os Panigo, D. (2000) "La Matriz Insumo-Producto" en Material para Trabajos Prácticos/Universidad Nacional de la Plata [En Línea]. Argentina, disponible en: http://perio.unlp.edu.ar/economiapolitica/material.html

os Pérez, E. (2001) "¿Una nueva ruralidad en América Latina?, Repensando el desarrollo rural" en CLACSO [En línea]. Argentina. Disponible en: http://bibliotecavirtual.clacso.org.ar/ar/libros/rural/rural.html

os Perico, R. y Ribero, M. (2002) Nueva Ruralidad, Visión del territorio en América Latina y el Caribe, Instituto Interamericano de cooperación para la agricultura [En Línea]. Disponible en: http://webiica.iica.ac.cr/ bibliotecas/repiica/B0536E/B0536E.PDF

os PNUD, (1995) "Informe sobre Desarrollo Humano 1995", en Informes sobre Desarrollo Humano. [En línea]. México, disponible en: http://hdr. undp.org/en/media/hdr_1995_es_cap1.pdf

os SNC-Lavalin International Inc. (2008) "Revisión de Estudios Sectoriales ACT-120" en FOMILENIO. [En línea]. El Salvador, disponible en: http:// www.mca.gob.sv/contenidolmagen.ashx? codigo $=118 \&$ tipo $=2$ 
1 Los cálculos han sido elaborados en base a los resultados obtenidos por el VI Censo de Población y V de Vivienda 2007. Se han obviado datos del resto de departamentos y municipios para fines demostrativos.

2 Para efectos de estandarización de indicadores del PDP, un empleo también es equivalente a 250 jornales agrícolas.

3 En esta área de análisis únicamente se incluyen a los jóvenes en razón de que éstos fueron los únicos considerados en el eje transversal de inclusión del proyecto.

4 La encuesta puede ser consultada en el Anexo V del trabajo de graduación.

5 El tipo de muestreo aplicado es de tipo no probabilístico, para lo cual se ha tomado en cuenta que 65 beneficiarios son más del $50 \%$ del total de beneficiarios.

6 Para el presente resumen ejecutivo, únicamente se presentan los resultados de cada componente, sin incluir los análisis realizados para cada uno de los indicadores propuestos en el plan de evaluación.

7 A pesar de que se realizaron varias consideraciones metodológicas en la elaboración de este instrumento, se consideró aceptable su realización para los fines acá propuestos.

8 Para dichos datos mensuales, se tomó como referencia diciembre de 2011.

9 Disponible en línea en: http://www.bcr. gob.sv/esp/index.php?option $=\mathrm{com}_{-}$ wrapper\&view $=$ wrapper\&Itemid $=308$

10 La serie de tiempo puede ser consultada en el ANEXO VI de la investigación. Los datos fueron tomados de la Base de Datos Económica de la página web del BCR de El Salvador.

11 Dicho estudio puede ampliarse a través del análisis de encadenamiento hacia atrás de los coeficientes de eslabonamiento de demanda por columna y por fila que se realiza en la sección 3.2.2.3.1. en el capítulo 3 de la investigación. 